\title{
A Study on Initial Setting and Modulus of Elasticity of AAM Mortar Mixed with CSA Expansive Additive Using Ultrasonic Pulse Velocity
}

\author{
Gum-Sung Ryu ${ }^{1, *}$, Sung Choi ${ }^{2}$, Kyung-Taek Koh ${ }^{1}$, Gi-Hong Ahn ${ }^{1}$, Hyeong-Yeol Kim ${ }^{1}$ and \\ Young-Jun You ${ }^{1}$ \\ 1 Department of Infrastructure Safety Research, Korea Institute of Civil Engineering and Building Technology, \\ 283 Goyangdae-Ro, Ilsanseo-Gu, Goyang-Si 10223, Korea; ktgo@kict.re.kr (K.-T.K.); \\ agh0530@kict.re.kr (G.-H.A.); hykim1@kict.re.kr (H.-Y.K.); yjyou@kict.re.kr (Y.-J.Y.) \\ 2 Department of Civil Engineering, KyungDong University 27, Gyeongdongdaehak-Ro, Yangju-Si 11458, \\ Korea; csomy1113@kduniv.ac.kr \\ * Correspondence: ryu0505@kict.re.kr; Tel.: +82-31-910-0050
}

Received: 31 August 2020; Accepted: 28 September 2020; Published: 5 October 2020

\begin{abstract}
This study investigated the hardening process of alkali-activated material (AAM) mortar using calcium sulfoalumiante (CSA) expansive additive (CSA EA), which accelerates the initial reactivity of AAMs, and subsequent changes in ultrasonic pulse velocity (UPV). After the AAM mortar was mixed with three different contents of CSA EA, the setting and modulus of elasticity of the mortar at one day of age, which represent curing steps, were measured. In addition, UPV was used to analyze each curing step. The initial and final setting times of the AAM mortar could be predicted by analyzing the UPV results measured for $14 \mathrm{~h}$. In addition, the dynamic modulus of elasticity calculated using the UPV results for $24 \mathrm{~h}$ showed a tendency similar to that of the static modulus of elasticity. The test results showed that the use of CSA EA accelerated the setting of the AAM mortar and increased the modulus of elasticity, and these results could be inferred using UPV. The proposed measurement method can be effective in evaluating the properties of a material that accelerates the initial reactivity.
\end{abstract}

Keywords: alkali-activated material; CSA expansive additive; ultrasonic pulse velocity; setting time; modulus of elasticity

\section{Introduction}

Alkali-activated materials (AAMs) are binders that accelerate the reaction of mineral admixtures, such as ground granulated blast furnace slag (GGBFS) and fly ash (FA), using strong alkali activators with high $\mathrm{pH}(>12)$. As AAMs are highly reactive, the hydrates of mineral admixtures are generated earlier. This lowers the fluidity of the mortar and causes setting and hardening at the same time. This process occurs quite suddenly [1-4]. The acceleration of the mortar setting has a significant impact on the physical properties of mortar at early ages [5-9], especially the initial shrinkage stress of the AAM mortar. According to the studies of many researchers, the shrinkage of mortar and concrete is evaluated after the occurrence of the final setting [10-14]. This is because the final setting means that the AAM matrix has been hardened and the deformation that occurs after the hardening of the AAM matrix acts as stress. Therefore, if the final setting of mortar that uses AAMs as binders is accelerated, shrinkage stress occurs earlier. This may cause significant initial shrinkage of the AAM mortar and high shrinkage stress. In addition, as the hydration reaction of AAMs is fast even after the final set, the strength and modulus of elasticity of the AAM mortar also significantly increase at early ages. The increase in the modulus of elasticity of the mortar causes a larger initial shrinkage stress. In general, 
additives, such as expansive additives (EAs) and shrinkage reducing agents, are used to control the shrinkage of mortar. These additives are effective in reducing shrinkage, but shrinkage stress can be evaluated differently if the setting and modulus of elasticity of mortar are considered [15]. In particular, when a calcium sulfoalumiante (CSA) expansive additive (CSA EA) is used, the formation of ettringite and calcium monosulfoaluminate at the initial stage can compensate for shrinkage, but it can also increase the modulus of elasticity and compressive strength [16-19]. If the setting is accelerated or the modulus of elasticity increases despite the reduction in shrinkage, the initial shrinkage stress of mortar can be evaluated to be larger [20]. Therefore, mortar and concrete that used AAMs require a comprehensive evaluation of the properties that can calculate the stress caused by deformation, such as setting, modulus of elasticity, and shrinkage at early ages.

In general, it is possible to measure the shrinkage of mortar before setting using an embedded strain gauge and a data logger. However, to measure the shrinkage stress of mortar, the modulus of elasticity at the time of the occurrence of shrinkage must also be considered.

The elastic modulus is determined from the load-displacement curve, as it is the slope of the curve. Nevertheless, the strength of concrete and mortar specimens is too low to be measured with mechanical tests, making it difficult to determine elastic modulus. In addition, as the strength and modulus of elasticity vary dramatically over time at early ages, the limited number of specimens to perform continuous monitoring may cause larger experimental errors [21-23]. The use of the ultrasonic pulse velocity (UPV), a type of non-destructive testing, can detect the physical properties of a specimen continuously and successively without causing damage. With respect to the analysis of the properties of concrete, UPV has been verified by many researchers [24-27]. Öztürk et al. detected the early hydration status of cement materials through ultrasonic reflectance measurements. They showed that changes in reflected waves responded well to various stages of hydration [28]. Voigt et al. conducted studies on changes in microstructure during cement hydration using ultrasonic reflection and transmission techniques $[29,30]$.

In addition, the use of UPV makes it possible to quantitatively analyze the hydration process of concrete. In particular, many researchers have reported that the setting time can be predicted using changes in the UPV curve [31-33]. Reinhardt and Grosse developed an ultrasonic device for concrete quality control testing that can continuously observe the characteristics of concrete. The results obtained using this device reported that the initial setting time can be determined by UPV [34]. Krauß and Hariri reported that the degree of hydration of concrete at the initial stage can be analyzed using UPV and proposed a method to predict the setting time [35]. Belie et al. conducted research on the setting and hardening of shotcrete mortar, for which the hydration reaction of the binder is significantly fast. They found that shotcrete mortar was immediately hardened in the fluid state, and they could analyze the sudden setting and hardening process of the mortar using UPV [36].

The use of UPV makes it possible to analyze the overall hardening process of concrete and mortar, and UPV has been used to analyze the static and dynamic elasticity characteristics as well as the tensile and compressive strengths of concrete and mortar [35,37-41]. Rajagopalan et al. reported that they identified highly reliable concrete characteristics at early ages using the relationship between the UPV and compressive strength of concrete at early ages [42]. Anderson and Seals conducted research to predict the long-term compressive strength of concrete through non-destructive testing using UPV and proposed a non-destructive test method for predicting the long-term strength [43]. Abdel-Jawed and Afaneh investigated various factors in concrete that affect the ultrasonic pulse. They mentioned that the compressive strength characteristics over time according to the water/binder (W/B) ratio can be analyzed using UPV [44]. Trtnik et al. investigated material and mix properties that affect the UPV of concrete and verified the relationship between UPV and the static/dynamic modulus of elasticity based on the results [39].

There have been attempts of measuring UPV as a means of exploring the fresh state and setting properties of ordinary Portland cement (OPC)-based concrete and mortar, while it has been rarely applied to the binders that set very rapidly. Determination of elastic modulus after the setting has 
occurred is particularly important for controlling the shrinkage-induced stress and crack formation. This study attempted to evaluate the initial physical properties of the AAM mortar using CSA EA, which affects the setting and modulus of elasticity of mortar despite its shrinkage compensation effect. It was possible to find the initial and final setting times of the AAM mortar in the UPV inflection section by measuring the UPV for $48 \mathrm{~h}$ and to identify changes in its modulus of elasticity from the final setting to $48 \mathrm{~h}$ through the relationship between the UPV and dynamic modulus of elasticity. Based on this, the relationship between the setting and modulus of elasticity of the AAM mortar was analyzed according to the content of CSA EA, which is used for shrinkage reduction.

\section{Materials and Methods}

\subsection{Materials and Mixture Proportions of AAM Mortar}

Table 1 shows the physical properties and chemical compositions of the ground granulated blast furnace slag (GGBFS), fly ash (FA), and calcium sulfoalumiante expansive additive (CSA EA) used in AAM mortar. GGBFS satisfied the third type of KS F2563 (density: $>2.8 \mathrm{~g} / \mathrm{cm}^{3}$, fineness: 4000-6000 $\mathrm{cm}^{2} / \mathrm{g}$ ), and FA met the second type of KS L5405 (density: $>1950 \mathrm{~g} / \mathrm{cm}^{3}$, fineness: $>3000 \mathrm{~cm}^{2} / \mathrm{g}$ ). Both GGBFS and FA were produced by the company Sampyo in South Korea $[45,46]$. The CSA EA used in this study was POWER CSA TYPE from Denka in Japan. It was used to compensate for the shrinkage of the AAM mortar and was added on the basis of the binder mass. The main chemical components of GGBFS were $\mathrm{CaO}(41.9 \%), \mathrm{SiO}_{2}(13.8 \%)$, and $\mathrm{Al}_{2} \mathrm{O}_{3}(4.9 \%)$. Its basicity coefficient $\left(\mathrm{K}_{\mathrm{b}}=(\mathrm{CaO}+\right.$ $\left.\mathrm{MgO}) /\left(\mathrm{SiO}_{2}+\mathrm{Al}_{2} \mathrm{O}_{3}\right)\right)$ and hydration modulus $\left(\mathrm{HM}=\left(\mathrm{CaO}+\mathrm{MgO}+\mathrm{Al}_{2} \mathrm{O}_{3}\right) / \mathrm{SiO}_{2}\right)$ were 0.99 and 1.82 , respectively. $\mathrm{K}_{\mathrm{b}}$ was close to 1.0 , which is a neutral value for ideal alkali activation, and $\mathrm{HM}$ was higher than 1.4, which is a value for excellent hydration reaction. FA was composed of $\mathrm{SiO}_{2}(56.8 \%)$, $\mathrm{Al}_{2} \mathrm{O}_{3}(22.8 \%), \mathrm{Fe}_{2} \mathrm{O}_{3}(6.9 \%)$, and $\mathrm{M}_{2} \mathrm{O}\left(\mathrm{K}_{2} \mathrm{O}+\mathrm{Na}_{2} \mathrm{O}\right)(1.9 \%)$. The main components of CSA EA were lime, gypsum, and bauxite, and they were composed of $\mathrm{CaO}(34.6 \%), \mathrm{SiO}(30.2 \%)$, and $\mathrm{Al}_{2} \mathrm{O}_{3}(24.2 \%)$. The alkali activator was used to accelerate the reaction of the binder. The alkali activator was in the form of a white powder with a molar ratio of 0.95 . In addition, alkali activators are manufactured separately by adjusting the chemical components. The $\mathrm{SiO}_{2} / \mathrm{Na}_{2} \mathrm{O}$ ratio of the alkali activator used in this study was 0.92 . The fine aggregate used was river sand with a density of 2.53 , water absorptivity of 1.08 , and fineness modulus of 2.77 .

Table 1. Physical properties and chemical composition of alkali-activated material (AAM) binder and calcium sulfoalumiante expansive additive (CSA EA).

\begin{tabular}{|c|c|c|c|c|c|c|c|c|c|c|}
\hline Type & $\begin{array}{l}\text { Density } \\
\left(\mathrm{g} / \mathrm{cm}^{3}\right)\end{array}$ & $\begin{array}{c}\text { Blaine Specific Surface } \\
\left(\mathrm{cm}^{2} / \mathrm{g}\right)\end{array}$ & $\mathrm{CaO}$ & $\mathrm{SiO}_{2}$ & $\mathrm{Al}_{2} \mathrm{O}_{3}$ & $\mathrm{Fe}_{2} \mathrm{O}_{3}$ & $\mathrm{SO}_{3}$ & $\mathrm{MgO}$ & $\mathrm{K}_{2} \mathrm{O}$ & $\mathrm{Na}_{2} \mathrm{O}$ \\
\hline GGBFS & 2.9 & 4680 & 43.4 & 34.6 & 14.3 & 0.6 & 5.0 & 5.1 & 0.5 & 0.2 \\
\hline FA & 2.2 & 3220 & 3.5 & 56.8 & 22.8 & 6.9 & 0.5 & 1.8 & 1.1 & 0.8 \\
\hline $\begin{array}{l}\text { CSA expansive } \\
\text { additive }\end{array}$ & 2.9 & 3750 & 36.4 & 30.2 & 24.2 & 1.7 & 5.3 & 1.4 & 0.5 & 0.3 \\
\hline Alkali activator & 1.0 & - & - & 46.2 & - & - & - & - & - & 50.2 \\
\hline
\end{tabular}

Table 2 summarizes the mix proportions of the AAM mortar. A binary blended binder in which GGBFS and FA were mixed at a ratio of 7:3 was used, and $24 \%$ alkali activator was used compared to the unit water content. The contents of CSA EA used were $0 \%, 2.5 \%, 5.0 \%$, and $7.5 \%$ compared to the amount of the binder. The water/binder (W/B) ratio was $45.1 \%$, and the sand/binder $(\mathrm{S} / \mathrm{B})$ ratio was 1.2 . For the mixing method, the basic binder, alkali activator, and CSA EA were placed in a test container and dry mixing was performed for $30 \mathrm{~s}$. Then, water was added, and mixing was performed for ten min at $150 \mathrm{rpm}$ to produce paste. In addition, fine aggregate was added, and mixing was performed for $90 \mathrm{~s}$ at $300 \mathrm{rpm}$. 
Table 2. Mix proportions of alkali-activated material (AAM) mortar.

\begin{tabular}{cccccc}
\hline \multirow{2}{*}{ Type } & Water & Binder & Activator & Sand & CSA \\
\cline { 2 - 6 } & $\mathbf{( g )}$ & $\mathbf{( g )}$ & $\mathbf{( g )}$ & $\mathbf{( g )}$ & $\mathbf{( g )}$ \\
\hline 0 EA & 0.451 & 1.000 & 0.108 & 1.200 & 0.000 \\
2.5 EA & 0.451 & 1.000 & 0.108 & 1.200 & 0.250 \\
5.0 EA & 0.451 & 1.000 & 0.108 & 1.200 & 0.500 \\
7.5 EA & 0.451 & 1.000 & 0.108 & 1.200 & 0.750 \\
\hline
\end{tabular}

\subsection{Test Methods}

\subsubsection{Setting Time Test}

To evaluate the setting characteristics of the AAM mortar, the mortar Vicat test was conducted in accordance with ASTM C191-18a [47]. The initial and final settings of the AAM mortar were determined using the penetration depth of the Vicat needle (diameter: $1.00 \pm 0.05 \mathrm{~mm}$, length: $50 \mathrm{~mm}$ or more) in a mortar for $30 \mathrm{~s}$. The Vicat needle penetration tests were conducted every five min, and the time at which no trace of the Vicat needle was observed on the AAM mortar surface was determined as the final setting time.

\subsubsection{Compressive Strength Test}

The compressive strength test was conducted in accordance with ASTM C109-16a [48]. The diameter and height of the cylindrical specimens were 100 and $200 \mathrm{~mm}$, respectively, and the tests were conducted at curing ages of 1,7 , and 28 days. The average compressive strengths of the three specimens were used. The specimens were cured in a constant temperature and humidity chamber at a temperature of $23 \pm 2{ }^{\circ} \mathrm{C}$ and a relative humidity of $90 \pm 2 \%$.

\subsubsection{Modulus of Elasticity Test}

The concrete modulus of elasticity test was conducted in accordance with ASTM C469M-14 [49]. The diameter and height of the cylindrical specimens were 100 and $200 \mathrm{~mm}$, respectively. Two strain gauges were attached to the side of each specimen to measure the modulus of elasticity. A load of up to $40 \%$ of the ultimate load was applied at a rate of $0.25 \mathrm{MPa} / \mathrm{s}$, and the modulus of elasticity was calculated through regression based on the interpolation of strain measurements for the load. The modulus of elasticity test results was obtained by averaging the modulus of elasticity measurement results of three specimens. The specimens were cured in a constant temperature and humidity chamber at a temperature of $23 \pm 2{ }^{\circ} \mathrm{C}$ and a relative humidity of $90 \pm 2 \%$.

\subsubsection{Ultrasonic Pulse Value (UPV) Test}

The system used for monitoring the UPV in the AAM mortar specimens is shown in Figure 1. A hole was made in the Styrofoam container, and an oscillator and a receiver were placed so that they could face each other at a distance of $30 \mathrm{~mm}$. After filling the container with mortar, the transit time of ultrasonic waves from the oscillator to the receiver was measured every $30 \mathrm{~s}$. The Pundit-2 model from PROCEQ was used to measure the UPV. UPV $\left(\mathrm{V}_{\mathrm{c}}\right)$ was obtained by dividing the length of the specimen $(\mathrm{L})$ by the transit time $(\mathrm{T})$, and it has the following relationship with the dynamic modulus of elasticity $\left(\mathrm{E}_{\mathrm{d}}\right)$ and density $(\rho)$ [50-52].

$$
V_{c}=\frac{\mathrm{L}}{\mathrm{T}}=\sqrt{\frac{E_{d}}{\rho}}
$$

Figure 2 shows the typical evolution curve of the UPV of the AAM mortar, which was altered with three sections. According to the curve, points A and B can be determined in terms of altered time 
points. The UPV begins to increase at point $A$, and it begins to slow down and converges to a certain value at point $B$ [53-55].

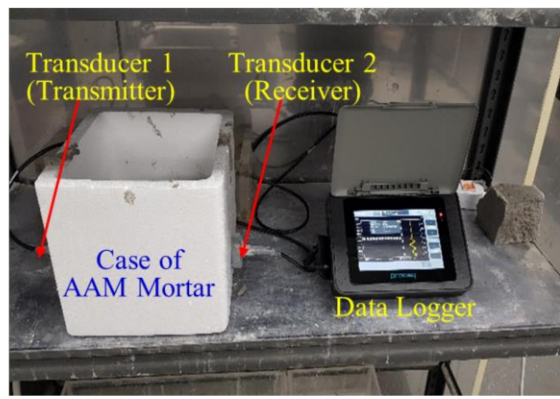

Figure 1. Schematic of ultrasonic pulse velocity (UPV) monitoring.

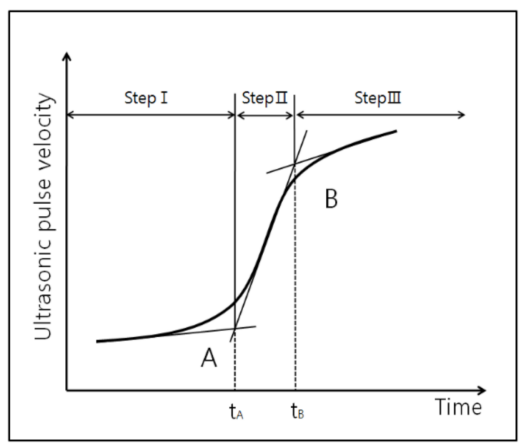

Figure 2. Typical evolution curve of ultrasonic pulse velocity.

\section{Results and Discussion}

\subsection{Setting Time}

The setting of AAM mortar is affected by the conditions of the alkali activator, and it is generally faster than that of ordinary Portland cement (OPC) [56,57]. Table 3 shows the setting time of the AAM mortar according to the content of EA. For 0 EA without EA, the initial setting time (IST) was $101 \mathrm{~min}$ and the final setting time (FST) was $292 \mathrm{~min}$. As for paste $(\mathrm{w} / \mathrm{c}=0.5)$ using ordinary Portland cement (OPC), the initial setting is within 6 to $7 \mathrm{~h}$ according to the literature [58]. Under the same mixing conditions, the AAM mortar exhibited a faster setting compared to mortar that used cement as a binder. This is because the alkali activator stimulated the binder quite early [59].

Table 3. Setting time and strength characteristics of the AAM mortar mixed with EA.

\begin{tabular}{ccccccc}
\hline \multirow{2}{*}{ Type } & \multicolumn{2}{c}{ Setting Time } & \multicolumn{2}{c}{ Compressive Strength } & \multicolumn{2}{c}{ Modulus of Elasticity } \\
\cline { 2 - 8 } & \multicolumn{2}{c}{$\mathbf{( m i n )}$} & \multicolumn{2}{c}{$\mathbf{( M P a )}$} & \multicolumn{2}{c}{$\mathbf{( E _ { \mathbf { s } } , \mathbf { G P a } )}$} \\
\cline { 2 - 8 } & IST & FST & 1D & 28D & 1D & 28D \\
\hline 0 EA & 101 & 292 & 3.2 & 43.6 & 1.7 & 19.3 \\
2.5 EA & 93 & 238 & 5.2 & 49.1 & 2.1 & 20.1 \\
5.0 EA & 70 & 223 & 5.9 & 49.6 & 2.3 & 20.2 \\
7.5 EA & 55 & 171 & 5.7 & 47.3 & 2.5 & 20.2 \\
\hline
\end{tabular}

The setting time was accelerated as the CSA EA content increased. For 7.5 EA with the highest CSA EA content, the initial setting time and final setting time were 55 and $171 \mathrm{~min}$, respectively, which were $45.4 \%$ and $41.4 \%$ shorter compared to those of 0 EA. When a CaO-based CSA EA is used in mortar, $\mathrm{Ca}^{2+}$ ions diffuse and generate hydrates $\left(\mathrm{Ca}(\mathrm{OH})_{2}\right)$. The setting characteristic of OPC is highly 
associated with the hydration of $\mathrm{C}_{3} \mathrm{~S}\left(\mathrm{Ca}_{3} \mathrm{SiO}_{5}\right.$, alite). An OPC paste reaches its initial setting state once $\mathrm{C}_{3} \mathrm{~S}$ has been sufficiently hydrated, and the final setting occurs when a sufficient amount of C-S-H has precipitated. On the other hand, the main constituent of CSA expansive additives is $\mathrm{C}_{4} \mathrm{~A}_{3} \mathrm{~s}\left(\mathrm{Ye}^{\prime}\right.$ elimite), which dissolves in contact with water and forms ettringite $\left(\mathrm{Ca}_{6} \mathrm{Al}_{2}\left(\mathrm{SO}_{4}\right)_{3}(\mathrm{OH})_{12} \cdot 26 \mathrm{H}_{2} \mathrm{O}\right)$ at a much faster rate than $\mathrm{C}_{3} \mathrm{~S}$ does.

This action, which is similar to the alkali activation reaction of AAM, accelerates the reaction of AAM by increasing the dissolution of $\mathrm{Ca}^{2+}$ ions in the mixing water, thereby further accelerating setting $[59,60]$.

\subsection{Compressive Strength and Modulus of Elasticity}

When a CSA EA is used in mortar, the mortar temporarily expands at the initial stage owing to the hydrates of EA, and its internal structure becomes dense. This increases the strength and modulus of elasticity of the mortar [1]. Table 3 shows the compressive strength and modulus of elasticity of AAM mortar mixed with CSA EA.

The average compressive strength of the three AAM mortars exceeded $40 \mathrm{MPa}$, which was the target strength set during the mix design. The AAM mortar without EA (0 EA) exhibited high initial strength, with a compressive strength of $3.2 \mathrm{MPa}$ and modulus of elasticity of $1.2 \mathrm{GPa}$ at 1 day of age. However, for the AAM mortar mixed with CSA EA, the compressive strength was higher than $5 \mathrm{MPa}$, and the modulus of elasticity was higher than $2 \mathrm{GPa}$ at 1 day of age, which were 63-87\% and 76.3-103.5\% higher, respectively, compared to those of 0 EA. AAM mortar containing CSA EA exhibited higher compressive strength values at 28 days of age compared to $0 \mathrm{EA}$. At one day of age, the strength and modulus of elasticity increased as the EA content increased. However, at 28 days of age, the compressive strength of 5.0 EA was the highest (49.6 MPa), and the compressive strength of 7.5 EA was $47.3 \mathrm{MPa}$, which was lower than that of $2.5 \mathrm{EA}$.

When the modulus of elasticity of the AAM mortar at 28 days of age was compared, the modulus of elasticity of the AAM mortar containing CSA EA was higher than that of 0 EA, but there was no clear improvement in the modulus of elasticity due to EA. This is because the modulus of elasticity was not significantly affected by the binder, as it was also affected by factors other than the cement matrix, such as fine aggregate.

\subsection{Ultrasonic Pulse Velocity}

UPV can measure changes in the internal structure of mortar caused by a hydration reaction without physical damage using the speed of sound waves, and it is possible to identify sudden changes in the internal structure of mortar through the monitoring of UPV. According to Lee et al., the UPV of mortar and concrete has three different sections [61]. The initial fluid state section (step 1) represents the unhardened state of the mortar. In this instance, the UPV exhibits a level similar to that of the fluid state and ranges from 300 to $500 \mathrm{~m} / \mathrm{s}$. In step 2, pores are filled with the hydration products of cement, and moisture unsaturated porous solid structures are connected, thereby increasing the UPV. In the step 3 section, high UPV is maintained because the hydrates are connected to each other, and mortar begins to develop strength owing to the curing process. Micropores are filled with hydration products, and UPV continuously increases, even though it does not increase as rapidly as in step 2.

Figure 3 shows the UPV curves of the AAM mortar according to the EA content. The UPV of the AAM mortar incorporating CSA EA was 348-412 m/s, corresponding to the values typically shown by a mixture in the fluid state. An increase in the UPV value was observed after $0.5 \mathrm{~h}$ by $7.5 \mathrm{EA}$, which incorporated the highest dosage of CSA EA and was the first to enter step 2, followed by 2.5 EA and 0 EA after $1.5 \mathrm{~h}$. It was observed that the UPV rapidly increased in step 2, while its increasing rate decreased after 3-8 h, reaching step 3. Similarly, the time taken to reach step 3 was the shortest in 7.5 EA. The rate at which the UPV increased tended to gradually decrease $48 \mathrm{~h}$ after the specimens reached step 3 . 


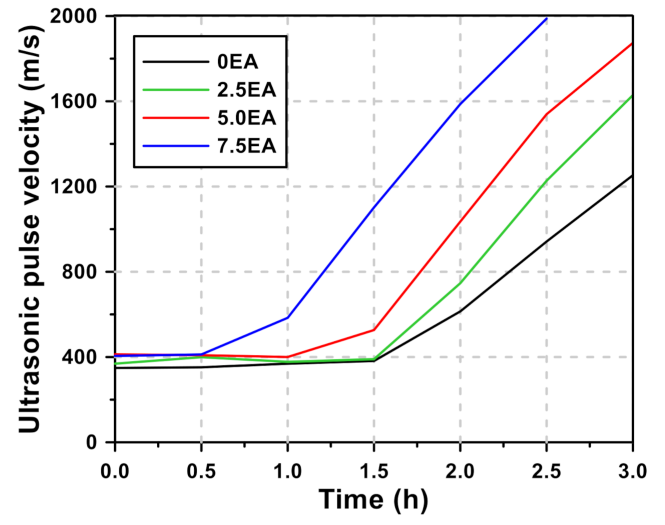

(a)

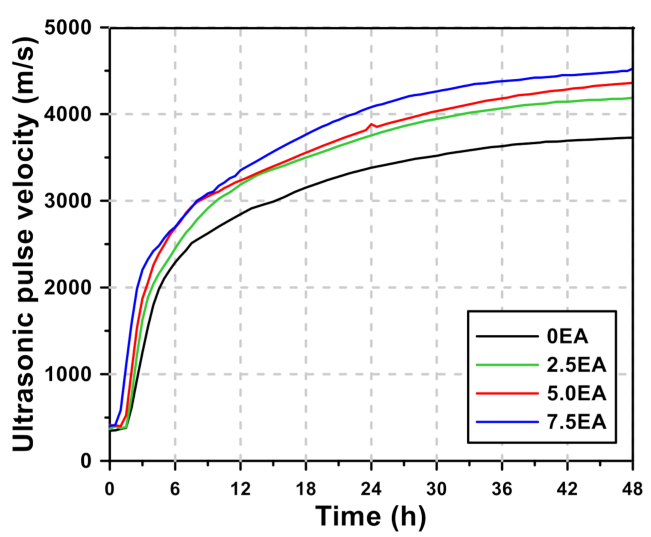

(b)

Figure 3. AAM mortar of ultrasonic pulse velocity curve: (a) Time: $3 \mathrm{~h}$, (b) Time: $48 \mathrm{~h}$.

The curves show shapes similar to those of the UPV curves of other researchers, but there are some differences. In a study by Lee et al. [61], the duration of step 1 for OPC mortar was 6-10 h, whereas that for the AAM mortar was $0.5-1.5 \mathrm{~h}$, suggesting that the duration of step 1 was much shorter for AAM. In addition, while step 2 was reached after a sudden increase from step 1 for the UPV curves of the AAM mortar, the UPV curves of the OPC mortar continuously increased without clear boundary points to reach step 2. This is because the rapid hydration reaction occurred as AAM mortar-stimulated GGBFS using the alkali activator. In addition, CSA EA further reduced step 1 as it accelerated the hydration reaction. Lee et al. [61] suggested that OPC mortar reaches step 3 after $16-20 \mathrm{~h}$, while it was shown that AAM took 3-8 h to reach step 3, showing a much faster rate than OPC mortar. This is because the rapid reaction of AAM mortar occurred as described above. The AAM mortar containing EA exhibited a higher UPV at the same age. This is due to the generation of ettringite, which is the main hydration product of EA.

\subsection{Setting Time in UPV Test}

The UPV curve can reflect changes in the internal structure of mortar caused by the hydration reaction. Pessiki and Carino et al. analyzed the relationship between UPV and setting or strength using the UPV curve [62]. According to a report by Lee et al., the analysis of the relationship between the UPV and the setting of concrete revealed that UPV increased when setting began. It was confirmed that initial and final settings occurred when UPV reached certain values $[61,63,64]$.

The UPV measurement for AAM according to each step defined in Figure 2 is analyzed in Figure 4. As can be seen from the figure, the UPV curves are divided into three sections. According to a report by Lee, the intersections of the straight lines created by connecting UPV values in each section are related to setting. As the UPV curves of the AAM mortar have three different sections, straight lines were created in each section by connecting the data, and the intersections of the lines were compared with the setting time by the ASTM C191-18a test method.

Step 1 lasted for approximately $60 \mathrm{~min}$ (30 $\mathrm{min}$ for EA7.5), and the UPV results were used to create a straight line (black curve in Figure 4). The UPV sharply increased afterwards, and step 2 began approximately 90-120 min after mixing. In this instance, the use of EA advanced the time at which step 2 began. During step 2, the UPV results for an hour were used to create a straight line (blue curve in Figure 4). Step 3 began approximately eight hours after mixing. Mortar mixtures tend to reach step 3 within $3-8 \mathrm{~h}$ after setting. The point at which the UPV converges has been determined by regression analysis (blue curve in Figure 4). 


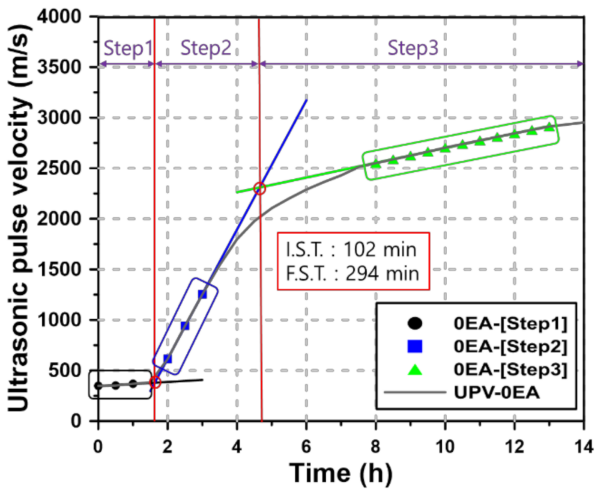

(a)

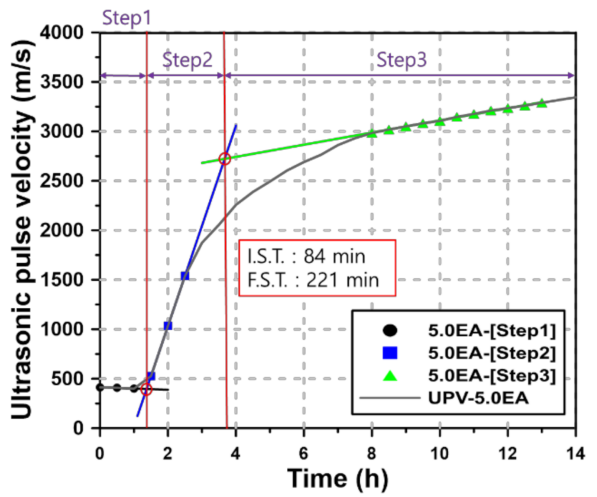

(c)

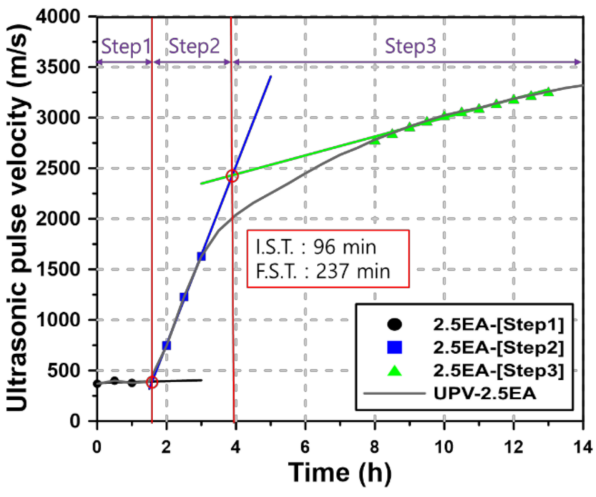

(b)

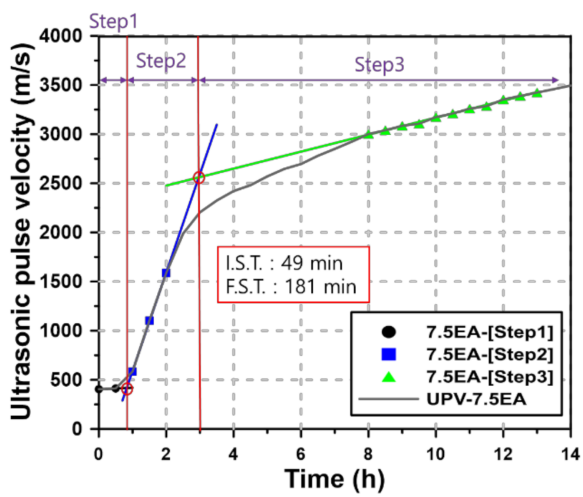

(d)

Figure 4. UPV curves of AAM mortar: (a) 0 EA, (b) 2.5 EA, (c) 5.0 EA, (d) 7.5 EA.

To determine the setting time of the AAM mortar using the UPV curves, the intersections of the straight lines created in each section of the curves were examined. The intersection of the straight lines of the step 1 and step 2 sections was defined as the initial setting, and that of the straight lines of the step 2 and step 3 sections was defined as the final setting. The analysis results showed that the initial setting time of 0 EA was $102 \mathrm{~min}$, and its final setting time was $294 \mathrm{~min}$. In the same manner, the initial setting and final setting of 2.5,5.0, and 7.5 EA are shown in each graph. The initial and final setting times determined using UPV became shorter as the EA content increased. Table 4 shows the differences between the initial and final setting times determined by the UPV curves and those determined by ASTM C 191-18a. The difference in initial setting time ranged from 1 to $14 \mathrm{~min}$, and that in the final setting ranged from 1 to $10 \mathrm{~min}$. In particular, when the EA content was $2.5 \%$ or less, the difference in setting time was 3 min or less, resulting in no significant difference in the results of the two test methods.

Table 4. Differences in setting time between the ASTM C 191-18a test method and UPV.

\begin{tabular}{ccccc}
\hline \multirow{2}{*}{ Type } & \multicolumn{4}{c}{ ASTM C 191-18a-UPV (min) } \\
\cline { 2 - 5 } & 0 EA & 2.5 EA & 5.0 EA & 7.5 EA \\
\hline IST * $^{*}$ & 1 & 3 & 14 & 6 \\
FST $^{* *}$ & 2 & 1 & 2 & 10 \\
\hline
\end{tabular}

IST *: Initial setting time; FST **: Final setting time.

\subsection{Elasticity in UPV Test}

The dynamic modulus of elasticity of mortar can be obtained through an empirical equation if dynamic characteristics, such as UPV, are used.

$$
E_{d}=\rho V_{c}^{2}
$$


where $E_{d}$ is the dynamic modulus of elasticity (GPa), $\rho$ is the density of the specimen (ton $/ \mathrm{m}^{3}$ ), and $V_{c}$ is UPV $(\mathrm{m} / \mathrm{s})$. Table 5 shows the UPV results of the AAM mortar at one day of age, the $E_{\mathrm{d}}$ values obtained using the results, and the static modulus of elasticity $\left(E_{s}\right)$ values at one day of age obtained through an experiment. The density of the AAM mortar used was 2.4 ton $/ \mathrm{m}^{3}$.

Table 5. UPV and dynamic and static moduli of elasticity of the AAM mortar at one day of age.

\begin{tabular}{|c|c|c|c|c|c|c|}
\hline \multirow{3}{*}{ Type } & \multicolumn{3}{|c|}{ By UPV Test (1D) } & \multicolumn{2}{|c|}{ By ASTM C469M-14 (1D) } & \multirow{3}{*}{$\mathrm{E}_{\mathrm{d}} / \mathrm{E}_{\mathrm{s}}$} \\
\hline & \multirow{2}{*}{ UPV (m/s) } & \multirow{2}{*}{$\mathrm{E}_{\mathrm{d}}(\mathrm{GPa})$} & Increase Rate & \multirow{2}{*}{$\mathrm{E}_{\mathrm{s}}(\mathrm{GPa})$} & \multirow{2}{*}{$\begin{array}{c}\text { Increase Rate } \\
(0 \text { EA) }\end{array}$} & \\
\hline & & & (0 EA) & & & \\
\hline $0 \mathrm{E}$ & 3381.9 & 2.68 & 100.0 & 1.65 & 100.0 & 1.624 \\
\hline $2.5 \mathrm{E}$ & 3753.5 & 3.31 & 123.5 & 2.13 & 129.1 & 1.554 \\
\hline $5.0 \mathrm{E}$ & 3883.9 & 3.54 & 132.1 & 2.27 & 137.6 & 1.560 \\
\hline $7.5 \mathrm{E}$ & 4081.1 & 3.91 & 145.9 & 2.46 & 149.1 & 1.589 \\
\hline
\end{tabular}

As the EA content increased at 1 day of age, both $E_{d}$ and $E_{s}$ increased. As the content of CSA EA increased to $2.5,5.0$, and $7.5 \%, E_{\mathrm{s}}$ increased by 23.5, 32.1, and $45.9 \%$ compared to that of 0 EA and $E_{d}$ increased by 29.1, 37.6, and 49.1\%. Here, the difference between the increase rates of $E_{d}$ and $E_{S}$ of the AAM mortar that used CSA EA based on 0 EA ranged from 3.2\% to 5.6\%, indicating that $E_{d}$ and $E_{S}$ showed relatively similar tendencies. This means that $\mathrm{E}_{\mathrm{s}}$ can be indirectly calculated through UPV because $E_{d}$ is obtained using the equation of UPV. This approach has been mainly used to analyze the characteristics of rocks, and the correlation between the static and dynamic characteristics of rocks has been verified by several researchers [65-69].

In general, the dynamic modulus of elasticity tends to be higher than the static modulus of elasticity [65,70-72]. This can be because an increase in the crack and pore volume in concrete and mortar decreases their static modulus of elasticity to a larger extent $[65,73]$. In the test results, $E_{d}$ by UPV exhibited higher results than $E_{\mathrm{S}}$. It was found that $\mathrm{E}_{\mathrm{d}}$ was $62.4-55.4 \%$ higher than $\mathrm{E}_{\mathrm{s}}$.

Table 6 shows the static modulus of elasticity of the AAM mortar at the final setting time obtained using UPV. The UPV at the accurate final setting time was unknown because it was measured every 30 min. Therefore, the dynamic modulus of elasticity was calculated using UPV at a time point similar to the final setting time. At the final setting time of the AAM mortar, UPV exhibited similar values, ranging from 2039.9 to $2205.0 \mathrm{~m} / \mathrm{s}$. Based on this, the dynamic modulus of elasticity was measured to be between 0.98 and 1.14 GPa. The AAM mortar developed stiffness as it was cured, and UPV and the dynamic modulus of elasticity were found to be constant at the final setting time. They were similar regardless of EA content.

Table 6. UPV and dynamic modulus of elasticity at the final setting time of the AAM mortar.

\begin{tabular}{ccccc}
\hline Type & $\begin{array}{c}\text { By ASTM C 191-18a } \\
\text { Final Setting (h:m) }\end{array}$ & Time & $\begin{array}{c}\text { By UPV Test } \\
\text { UPV(m/s) }\end{array}$ & E $_{\mathbf{s}}$ (GPa) \\
\hline 0 EA & $4: 52$ & $5: 00$ & 2105.1 & 1.04 \\
2.5 EA & $3: 58$ & $4: 00$ & 2039.9 & 0.98 \\
5.0 EA & $3: 43$ & $3: 30$ & 2056.6 & 0.99 \\
7.5 EA & $2: 51$ & $3: 00$ & 2205.0 & 1.14 \\
\hline
\end{tabular}

\section{Conclusions}

In this study, the initial hardening characteristics of alkali-activated material (AAM) mortar were analyzed using the four levels of CSA expansive additive (CSA EA) content. For the analysis of the initial hardening characteristics using ultrasonic pulse velocity (UPV), the results of the Vicat setting test, a conventional test method, were compared with those of the modulus of elasticity test. The main observations and findings of this study can be summarized as follows: 
1. CSA EA is used to compensate for initial shrinkage, but it accelerates the initial reactivity and shortens the setting time, thereby causing the final setting, which is the basis of shrinkage stress. The dynamic modulus of elasticity of the AAM mortar obtained using UPV at the final setting time was approximately $1 \mathrm{GPa}$, which was constant regardless of the CSA EA content. As the modulus of elasticity of the AAM mortar increases over time, CSA EA that accelerates the final setting may cause high shrinkage stress at early ages.

2. The compressive strength of the AAM mortar tended to increase with the CSA EA up to the dosage level of $5.0 \%$, whereas it decreased at a dosage of $7.5 \%$. Therefore, it is concluded that the maximum dosage of CSA EA should be limited to $5.0 \%$, considering its effect on the compressive strength development.

3. The initial and final setting times obtained by the UPV test were similar to those obtained by the Vicat test. The dynamic modulus of elasticity derived through UPV increased as the CSA EA content increased, and it exhibited increase rates similar to those of the static modulus of elasticity. Therefore, UPV can reflect the curing, initial setting, and final setting processes of AAM mortar caused by the initial alkali activation reaction, and it is possible to evaluate the degree of curing of AAM mortar through the dynamic modulus of elasticity.

4. The use of a UPV monitoring system makes it possible to continuously observe the curing process of mortar and to identify changes in the stiffness of AAM mortar using the dynamic modulus of elasticity at early ages when it is difficult to conduct the static modulus of elasticity test. These data are expected to be useful in evaluating the initial shrinkage stress of AAM mortars.

5. In addition, the relationship between UPV and the static modulus of elasticity was established through various tests according to the material properties. Based on this relationship, it will be possible to evaluate the stress acting on mortar due to the displacement caused by various causes at early ages.

Author Contributions: Conceptualization, G.-S.R., S.C.; setting time test, S.C., G.-H.A.; data analysis, S.C.; compressive strength \& modulus of elasticity test, G.-H.A., K.-T.K.; data analysis, G.-S.R., H.-Y.K. Y.-J.Y.; UPV test \& data analysis, S.C., G.-S.R.; writing, G.-S.R., S.C. All authors have read and agreed to the published version of the manuscript.

Funding: This research received no external funding.

Acknowledgments: This work was supported by the Korea Institute of Civil Engineering and Building Technology (Project No. 2020-60).

Conflicts of Interest: The authors declare no conflict of interest

\section{References}

1. Lee, N.K.; Lee, H.K. Setting and mechanical properties of alkali-activated fly ash slag concrete manufactured at room temperature. Constr. Build. Mater. 2013, 47, 1201-1209. [CrossRef]

2. Brough, A.R.; Holloway, M.; Sykes, J.; Atkinson, A. Sodium silicate-based alkali-activated slag mortars: Part II. The retarding effect of additions of sodium chloride or malic acid. Cem. Concr. Res. 2000, 30, 1375-1379. [CrossRef]

3. Ravikumar, D.; Neithalath, N. Reaction kinetics in sodium silicate powder and liquid activated slag binders evaluated using isothermal calorimetry. Thermochim. Acta 2012, 546, 32-43. [CrossRef]

4. Ravikumar, D.; Neithalath, N. Effects of activator characteristics on the reaction product formation in slag binders activated using alkali silicate powder and $\mathrm{NaOH}$. Cem. Concr. Comp. 2012, 34, 809-818. [CrossRef]

5. Garnier, V.; Corneloup, G.; Sprauel, J.M.; Perfumo, J.C. Setting time study of roller compacted concrete by spectral analysis of transmitted ultrasonic signals. NDT E Int. 1995, 28, 15-22. [CrossRef]

6. Li, Z.; Xiao, L.; Wei, X. Determination of concrete setting time using electrical resistivity measurement. J. Mater. Civ. Eng. 2007, 19, 423-427. [CrossRef]

7. Coppola, L.; Coffetti, D.; Crotti, E.; Candamano, S.; Crea, F.; Gazzaniga, G.; Pastore, T. The combined use of admixtures for shrinkage reduction in one-part alkali activated slag-based mortars and pastes. Constr. Build. Mater. 2020, 248, 118682. [CrossRef] 
8. Coppola, L.; Coffetti, D.; Crotti, E.; Gazzaniga, G.; Pastore, T. The Durability of One-Part Alkali-Activated Slag-Based Mortars in Different Environments. Sustainability 2020, 12, 3561. [CrossRef]

9. Tataranni, P.; Besemer, G.M.; Bortolotti, V.; Sangiorgi, C. Preliminary research on the physical and mechanical properties of alternative lightweight aggregates produced by alkali-activation of waste powders. Materials 2018, 11, 1255. [CrossRef]

10. Cartwright, C.; Rajabipour, F.; Radlińska, A. Shrinkage characteristics of alkaliactivated slag cements. J. Mater. Civ. Eng. 2015, 27, B4014007. [CrossRef]

11. Collins, F.; Sanjayan, J.G. Effect of pore size distribution on drying shrinking of alkali-activated slag concrete. Cem. Concr. Res. 2000, 30, 1401-1406. [CrossRef]

12. Ye, H.; Radlińska, A. Shrinkage mechanisms of alkali-activated slag. Cem. Concr. Res. 2016, 88, 126-135. [CrossRef]

13. Ma, Y.; Ye, G. The shrinkage of alkali activated fly ash. Cem. Concr. Res. 2015, 68, 75-82. [CrossRef]

14. Hojati, M.; Rajabipour, F.; Radlińska, A. Drying shrinkage of alkali activated fly ash: Effect of activator composition and ambient relative humidity. In Proceedings of the 4th International Conference on Sustainable Construction Materials and Technologies (SCMT4), Las Vegas, NV, USA, 7-11 August 2016.

15. Nguyen, T.B.T.; Chatchawan, R.; Saengsoy, W.; Tangtermsirikul, S.; Sugiyama, T. Influences of different types of fly ash and confinement on performances of expansive mortars and concretes. Constr. Build. Mater. 2019, 209, 176-186. [CrossRef]

16. Sharp, J.H.; Lawrence, C.D.; Yang, R. Calcium sulfoaluminate cements-Low-Energy cements, special cements or what? Adv. Cem. Res. 1999, 11,3-13. [CrossRef]

17. Lan, W.; Glasser, F.P. Hydration of calcium sulphoaluminate cements. Adv. Cem. Res. 1996, 8, 127-134. [CrossRef]

18. Ioannou, S.; Reig, L.; Paine, K.; Quillin, K. Properties of a ternary calcium sulfoaluminate-calcium sulfate-fly ash cement. Cem. Concr. Res. 2014, 56, 75-83. [CrossRef]

19. Winnefeld, F.; Martin, L.H.; Müller, C.J. Using gypsum to control hydration kinetics of CSA cements. Constr. Build. Mater. 2017, 155, 154-163. [CrossRef]

20. Choi, S.; Ryu, G.S.; Koh, K.T.; An, G.H.; Kim, H.Y. Experimental Study on the Shrinkage ehavior and Mechanical Properties of AAM Mortar Mixed with CSA Expansive Additive. Materials 2019, 12, 3312. [CrossRef]

21. Sant, G. Examining volume changes, stress development and cracking in cement based systems. Master's Thesis, Purdue University, West Lafayette, IN, USA, 2007.

22. Sant, G.; DehaDrai, M.; Bentz, D.; Lura, P.; Ferraris, C.F.; Bullard, J.W.; Weiss, J. Detecting the fluid-to-solid transition in cement pastes. Concr. Int. 2009, 31, 53-58.

23. Stark, J. Recent advances in the field of cement hydration and microstructure analysis. Cem. Concr. Res. 2011, 41, 666-678. [CrossRef]

24. Carrión, A.; Genovés, V.; Gosálbez, J.; Miralles, R.; Payá, J. Ultrasonic signal modality: A novel approach for concrete damage evaluation. Cem. Concr. Res. 2017, 101, 25-32. [CrossRef]

25. Sepehrinezhad, A.; Toufigh, V. The evaluation of distributed damage in concrete based on sinusoidal modeling of the ultrasonic response. Ultrasonics 2018, 89, 195-205. [CrossRef]

26. Wu, J.; Feng, M.; Ni, X.; Mao, X.; Chen, Z.; Han, G. Aggregate gradation effects on dilatancy behavior and acoustic characteristic of cemented rockfill. Ultrasonics 2019, 92, 79-92. [CrossRef]

27. Cao, S.; Yilmaz, E.; Song, W.; Xue, G. Assessment of acoustic emission and triaxial mechanical properties of rock-cemented tailings matrix composites. Adv. Mater. Sci. Eng. 2019, 1-12. [CrossRef]

28. Öztürk, T.; Kroggel, O.; Grübl, P.; Popovics, J.S. Popovics, Improved ultrasonic wave reflection technique to monitor the setting of cement-based materials. NDT E Int. 2006, 39, 258-263. [CrossRef]

29. Voigt, T.; Grosse, C.U.; Sun, Z.; Shah, S.P.; Reinhardt, H.W. Comparison of ultrasonic wave transmission and reflection measurements with P- and S waves on early age mortar and concrete. Mater. Struct. 2005, 38, 729-738. [CrossRef]

30. Voigt, T.; Ye, G.; Sun, Z.; Shah, S.P.; Van Breugel, K. Early age microstructure of Portland cement mortar investigated by ultrasonic shear waves and numerical simulation. Cem. Concr. Res. 2005, 35, 858-866. [CrossRef]

31. Zhu, J.; Cao, J.N.; Bate, B.; Khayat, K.H. Determination of mortar setting times using shear wave velocity evolution curves measured by the bender element technique. Cem. Concr. Res. 2018, 106, 1-11. [CrossRef] 
32. Renteria-Marquez, I.A.; Renteria-Marquez, A.; Tseng, B.T.L. A novel contact model of piezoelectric traveling wave rotary ultrasonic motors with the finite volume method. Ultrasonics 2018, 90, 5-17. [CrossRef]

33. Carette, J.; Staquet, S. Monitoring the setting process of mortars by ultrasonic $\mathrm{P}$ and S-wave transmission velocity measurement. Constr. Build. Mater. 2015, 94, 196-208. [CrossRef]

34. Reinhardt, H.W.; Grosse, C.U. Continuous monitoring of setting and hardening of mortar and concrete. Constr. Build. Mater. 2004, 18, 145-154. [CrossRef]

35. Krauß, M.; Hariri, K. Determination of initial degree of hydration for improvement of early-age properties of concrete using ultrasonic wave propagation. Cem. Concr. Compos. 2006, 28, 299-306. [CrossRef]

36. De Belie, N.; Grosse, C.U.; Kurz, J.; Reinhardt, H.W. Ultrasound monitoring of the influence of different accelerating admixtures and cement types for shotcrete on setting and hardening behavior. Cem. Concr. Res. 2005, 35, 2087-2094. [CrossRef]

37. Yoo, D.Y.; Park, J.J.; Kim, S.W.; Yoon, Y.S. Early age setting, shrinkage and tensile characteristics of ultra high performance fiber reinforced concrete. Constr. Build. Mater. 2013, 41, 427-438. [CrossRef]

38. Shariq, M.; Prasad, J.; Masood, A. Studies in ultrasonic pulse velocity of concrete containing GGBFS. Constr. Build. Mater. 2013, 40, 944-950. [CrossRef]

39. Trtnik, G.; Kavčič, F.; Turk, G. Prediction of concrete strength using ultrasonic pulse velocity and artificial neural networks. Ultrasonics 2009, 49, 53-60. [CrossRef]

40. Keating, J.; Hannant, D.J.; Hibbert, A.P. Correlation between cube strength, ultrasonic pulse velocity and volume change for oil well cement slurries. Cem. Concr. Res. 1989, 19, 715-726. [CrossRef]

41. Bogas, J.A.; Gomes, M.G.; Gomes, A. Compressive strength evaluation of structural lightweight concrete by non-destructive ultrasonic pulse velocity method. Ultrasonics 2013, 53, 962-972. [CrossRef]

42. Rajagopalan, P.R.; Prakash, J.; Narasimhan, V. Correlation between ultrasonic pulse velocity and strength of concrete. Indian Concr. J. 1973, 47, 416-418.

43. Anderson, D.A.; Seals, R.K. Pulse velocity as a predictor of 28- and 90-day strength. J. Proc. 1981, 78, 116-122.

44. Abel-Jawad, Y.A.; Afaneh, M. Factors affecting the relationship between ultrasonic pulse velocity and concrete compressive strength. Indian Concr. J. 1997, 71, 373-378.

45. KS F 2563. Ground Granulated Blast-Furnace Slag for Use in Concrete; Korean Standards: Seoul, Korea, 2019.

46. KS L5405. Fly Ash; Korean Standards: Seoul, Korea, 2018.

47. ASTM, C191-18a. Standard Test Methods for Time of Setting Hydraulic Cement by Vicat Needle; ASTM International: West Conshohocken, PA, USA, 2018.

48. ASTM C109-16a. Standard Test Method for Compressive Strength of Hydraulic Cement Mortars (Using 2-in. or [50-mm] Cube Specimens); ASTM International: West Conshohocken, PA, USA, 2016.

49. ASTM C469M-14. Standard Test Method for Static Modulus of Elasticity and Poisson's Ratio of Concrete in Compression; ASTM International: West Conshohocken, PA, USA, 2014.

50. Komlos, K.; Popovics, S.; Nürnbergerová, T.; Babal, B.; Popovics, J.S. Ultrasonic pulse velocity test of concrete properties as specified in various standards. Cem. Concr. Compos. 1996, 18, 357-364. [CrossRef]

51. Qixian, L.; Bungey, J.H. Using compression wave ultrasonic transducers to measure the velocity of surface waves and hence determine dynamic modulus of elasticity for concrete. Constr. Build. Mater. 1996, 10, 237-242. [CrossRef]

52. Lu, X.; Sun, Q.; Feng, W.; Tian, J. Evaluation of dynamic modulus of elasticity of concrete using impact-echo method. Constr. Build. Mater. 2013, 47, 231-239. [CrossRef]

53. Chotard, T.; Gimet-Breart, N.; Smith, A.; Fargeot, D.; Bonnet, J.P.; Gault, C. Application of ultrasonic testing to describe the hydration of calcium aluminate cement at the early age. Cem. Concr. Res. 2001, 31, 405-412. [CrossRef]

54. Smith, A.; Chotard, T.; Gimet-Breart, N.; Fargeot, D. Correlation between hydration mechanism and ultrasonic measurements in an aluminous cement: Effect of setting time and temperature on the early hydration. J. Eur. Ceram. Soc. 2002, 22, 1947-1958. [CrossRef]

55. Boumiz, A.; Vernet, C.; Tenoudji, F.C. Mechanical properties of cement pastes and mortars at early ages: Evolution with time and degree of hydration. Adv. Cem. Res. 1996, 3, 94-106. [CrossRef]

56. Chang, J.J. A study on the setting characteristics of sodium silicate-activated slag pastes. Cem. Concr. Res. 2003, 33, 1005-1011. [CrossRef]

57. Choi, S.; Lee, K.M. Influence of $\mathrm{Na}_{2} \mathrm{O}$ Content and $\mathrm{Ms}\left(\mathrm{SiO}_{2} / \mathrm{Na}_{2} \mathrm{O}\right)$ of Alkaline Activator on Workability and Setting of Alkali-Activated Slag Paste. Materials 2019, 12, 2072. [CrossRef] 
58. Nedeljković, M.; Li, Z.; Ye, G. Setting, strength, and autogenous shrinkage of alkali-activated fly ash and slag pastes: Effect of slag content. Materials 2018, 11, 2121. [CrossRef] [PubMed]

59. Chatterji, S. Mechanism of expansion of concrete due to the presence of dead-burnt $\mathrm{CaO}$ and $\mathrm{MgO}$. Cem. Concr. Res. 1995, 25, 51-56. [CrossRef]

60. Shi, C.; Day, R.L. A calorimetric study of early hydration of alkali-slag cements. Cem. Concr. Res. 1995, 25, 1333-1346. [CrossRef]

61. Lee, H.K.; Lee, K.M.; Kim, Y.H.; Yim, H.; Bae, D.B. Ultrasonic in-situ monitoring of setting process of high-performance concrete. Cem. Concr. Res. 2004, 34, 631-640. [CrossRef]

62. Pessiki, S.P.; Carino, N.J. Setting Time and Strength of Concrete Using the Impact-Echo Method. Mater. J. 1988, 85, 389-399.

63. Wei, S.; Yunsheng, Z.; Jones, M.R. Using the ultrasonic wave transmission method to study the setting behavior of foamed concrete. Constr. Build. Mater. 2014, 51, 62-74. [CrossRef]

64. Zhang, S.; Zhang, Y.; Li, Z. Ultrasonic monitoring of setting and hardening of slag blended cement under different curing temperatures by using embedded piezoelectric transducers. Constr. Build. Mater. 2018, 159, 553-560. [CrossRef]

65. King, M.S. Static and dynamic elastic properties of igneous and metamorphic rocks from the canadian shield. Int. J. Rock Mech. Min. Sci. 1983, 20, 237-241. [CrossRef]

66. Christaras, B.; Auger, F.; Mosse, E. Determination of the moduli of elasticity of rocks. Comparison of the ultrasonic velocity and mechanical resonance frequency methods with direct static methods. Mater. Struct. 1994, 27, 222-228. [CrossRef]

67. Ameen, M.S.; Smart, B.G.; Somerville, J.M.; Hammilton, S.; Naji, N.A. Predicting rock mechanical properties of carbonates from wireline logs (A case study: Arab-D reservoir, Ghawar field, Saudi Arabia). Mar. Pet. Geol. 2009, 26, 430-444. [CrossRef]

68. Martínez-Martínez, J.; Benavente, D.; García-del-Cura, M.A. Comparison of the static and dynamic elastic modulus in carbonate rocks. Bull. Eng. Geol. Environ. 2012, 71, 263-268. [CrossRef]

69. Sone, H.; Zoback, M.D. Mechanical properties of shale-gas reservoir rocks-Part 1: Static and dynamic elastic properties and anisotropy. Geophysics 2013, 78, 381-392. [CrossRef]

70. Simmons, G.; Brace, W.F. Comparison of static and dynamic measurements of compressibility of rocks. J. Geophys. Res. 1965, 70, 5649-5656. [CrossRef]

71. Eissa, E.A.; Kazi, A. Relation between static and dynamic young's moduli of rocks. Int. J. Rock Mech. Min. Sci. 1988, 25, 479-482. [CrossRef]

72. Ciccotti, M.; Mulargia, F. Differences between static and dynamic elastic moduli of a typical seismogenic rock. Geophys. J. Int. 2004, 157, 474-477. [CrossRef]

73. Cheng, C.H.; Johnston, D.H. Dynamic and static moduli. Geophys. Res. Lett. 1981, 8, 39-42. [CrossRef] 